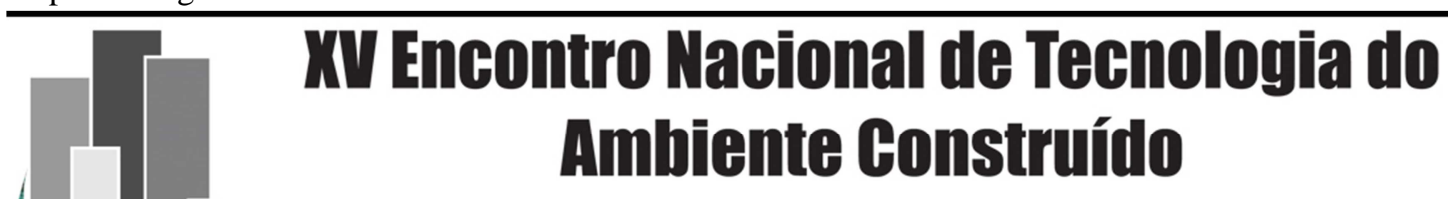

Avanços no desempenho das construções - pesquisa, inovação e capacitação profissional

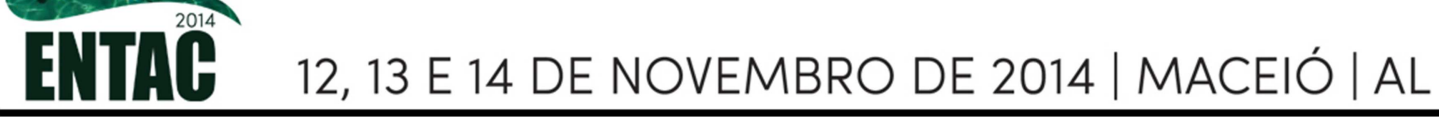

\title{
MÉTODO EXPERIMENTAL PARA ESTUDO DO CAMPO VISUAL DE USUÁRIOS DE PRAÇAS PÚBLICAS
}

\author{
SANTOS, Lúcia (1); CLARO, Anderson (2)
}

(1) UFSC, 4898002350, e-mail: arq.luciasantos@gmail.com (2) UFSC, e-mail: claro.ander@gmail.com.

\begin{abstract}
RESUMO
A iluminação gera condicionantes visuais que direcionam a implantação dos equipamentos de lazer em praças públicas. Uma destas condicionantes é a luz direta do Sol em relação ao campo visual dos usuários imposto pela posição dos equipamentos. Para o estudo de campo visual um dos métodos indicados é a obtenção de fotos com máquina fotográfica com lente olho de peixe a partir da posição do usuário, gerando uma imagem em projeção equidistante. Um dos métodos para análise da trajetória solar é a máscara solar vertical em projeção geométrica, não sendo compatíveis as projeções equidistantes das imagens de campo visual obtidas nas fotografias com lente olho de peixe. O presente estudo é parte dos dados de dissertação de Mestrado, e tem como objetivo apresentar uma ferramenta qualitativa para análise da posição solar vertical e horizontal compatível com a projeção equidistante, como método complementar ao estudo de implantação dos equipamentos de lazer presentes em praças públicas, através de 2 estudos de caso quanto ao sombreamento e a luz direta do Sol em relação ao campo visual. A metodologia é baseada na aquisição de fotografias da trajetória solar no sentido vertical, através de um solarscópio, com referência a diferentes orientações. Estas imagens foram inseridas no AutoCAD, onde foram elaboradas cartas solares verticais em projeção equidistante para diferentes orientações em relação ao norte e ao horizonte. Ao sobrepor a máscara solar vertical na foto do campo visual, pode-se visualizar a presença ou não da luz direta do sol, durante o ano, para o campo visual proposto. Como resultado espera-se possibilitar aos projetistas de espaços públicos, a partir destas informações, estudar a possibilidade de ocorrência ou não de desconforto visual causado pela luz direta do sol em relação aos campos visuais impostos por equipamentos de lazer.
\end{abstract}

Palavras-chave: Iluminação, Máscara Solar Vertical, Espaço Público.

\begin{abstract}
The lightning generates visual conditions that direct the implementation of the leisure equipment in public squares. One of these conditions is the direct sunlight in relation to the visual field of the users due to the position of the equipment. For the study of visual field one of the indicated methods is getting pictures with the fisheye lens camera, with a view from the position of the user generating an equidistant projected image. One of the methods for the analysis of solar trajectory is vertical solar mask in geometric projection, not compatible with the equidistant projections of the visual field images obtained on the fisheye lens photos. This study is part of the master's degree dissertation data base, and aims to present a qualitative tool for the analysis of both vertical and horizontal solar position compatible with the equidistant projection, as a complementary method to the study of implementation of leisure equipment located at public squares, regarding shading and direct sunlight in relation to visual field. The methodology is based on the acquisition of photos of the vertical solar trajectory, obtained with a solarscope, with reference many directions. These images were inserted in AutoCAD, where vertical solar letters in equidistant projection were created for different orientations in relation to north and horizon. By superimposing the vertical solar mask in the visual field picture, it is possible to visualize the presence or not of the direct sunlight, during the year, for the proposed visual field. As partial results it is expected to overlap photos of visual fields with the equidistant vertical solar trajectory, enabling designers of public spaces to study, through these information, the possibility of occurrence or not of visual discomfort caused by direct sunlight in relation to visual field imposed by leisure equipment.
\end{abstract}




\section{INTRODUÇÃO}

Com o decorrer dos anos e o avanço da urbanização, os habitantes das cidades passaram a apropriar-se do espaço público das cidades por um tempo maior, em relação ao cidadão de épocas anteriores à nossa. Por essa razão, há de se pensar a cidade visando não apenas em relação a locomoção das pessoas, mas uma adequação dos espaços urbanos livres para que sejam utilizados com mais frequência pela comunidade (SCHMITZ, 1997).

As praças públicas são espaços públicos utilizados tanto para o trânsito de pessoas quanto para o lazer, sendo que muitas delas servem como um elo unificador entre os diferentes locais das cidades. Sendo estas, local onde as pessoas interagem e podem ter alguns momentos de lazer, além de se deslocar de um local ao outro com flexibilidade (LIBERALINO, 2011).

Vários estudos quando tratam da iluminação do espaço urbano se baseiam no ambiente luminoso noturno (FROES, 2006; ROIZENBLATT, 2009; MOISINHO FILHO, 2010; MIER, 2013), e não se preocupam com a iluminação do espaço público durante o dia. Este estudo, porém, considera a iluminação natural de espaços públicos, assim como os autores Mascaró (2006) e Masbougi (2003), que consideram importante estudar e analisar a iluminação do espaço público diurna onde os contrates de luz e sombra também são constantes e cada equipamento de lazer tem uma necessidade diferente de sombreamento afetando diretamente a utilização dos equipamentos de lazer presentes em praças.

Este trabalho traz parte da Dissertação de Mestrado que ensaia um método para análise integrada das condições de iluminação diurna e noturna em praças, através da avaliação de dois estudos de caso.

Deste modo, este artigo apresenta a ferramenta gerada a partir da necessidade de analisar de forma qualitativa o movimento aparente do Sol no campo visual de usuários de praças públicas que este pudesse ser sobreposto a fotografias obtidas com lente olho de peixe, buscando detectar a possibilidade de ocorrência de ofuscamento. Ou seja, apresenta uma metodologia para a obtenção de carta solar vertical em projeção equidistante, que pode ser, também, reproduzida para diversas latitudes e direções de campo visual auxiliando na análise de sombreamento.

Busca-se, por meio dele, um método de análise inicial do espaço urbano que sirva de instrumento gráfico a arquitetos, urbanistas e projetistas. O objetivo é que este estudo contribua para a implantação adequada de equipamentos de lazer, de forma a utilizar o sombreamento gerado pela vegetação e entorno de maneira que minimize o ofuscamento causado pela luz direta do sol.

\section{MÉTODO}

O método proposto para desenvolvimento desta ferramenta baseia-se na necessidade de uma análise qualitativa do movimento aparente do Sol em projeção equidistante, para campos visuais impostos por equipamentos de praças públicas. 
A primeira etapa constitui-se em procurar um método prático e eficiente que represente de forma adequada o movimento aparente do sol. O solarscópio foi um dos objetos encontrados para auxiliar na execução das cartas solares verticais equidistantes. Portanto, propomos utilizar a máquina fotográfica com lente olho de peixe [a mesma utilizada para obter imagens de campo visual] para obter fotos do solarscópio, gerando assim imagens do movimento aparente do sol em projeção equidistante para diferentes direções em referência ao Norte. A comprovação e detalhamento do método será descrita a seguir.

A segunda etapa consiste no mapeamento das direções e ângulos de campo visual impostos pelos equipamentos de lazer a serem estudados. Em sequência, obtiveram-se as fotos do solarscópio em mesma direção e sentido dos ângulos de visão mapeados, editaram-se as imagens desenhando de forma técnica as cartas solares em projeção equidistante.

Como última etapa, foi realizada a sobreposição da carta solar à imagem de campo visual de mesma direção, obtendo figuras para a análise do movimento do sol para aquele campo de visão e seu sombreamento. A possibilidade ocorrência de ofuscamento no olho humano, causado pela incidência direta da luz do sol é a matéria principal deste trabalho.

\subsection{Validação do Método}

A ferramenta utilizada para se obter as cartas solares verticais foi o solarscópio (Figura 1). Objeto este, utilizado para simulação do movimento aparente do sol com maquetes físicas, sendo uma alternativa aos arquitetos e projetistas para estudar a insolação e as diferentes formas de incidência da luz do sol em determinado projeto, seja ele urbano ou de edificações (LABCON, 2014).

A Figura 1 mostra o solarscópio utilizado, com 33 lâmpadas, sendo 11 para cada época do ano, são três madeiras curvas representando os solstícios de inverno e verão e o equinócio. Com 11 lâmpadas em cada curva apontando a posição do sol desde as 7 horas às 17 horas, observando que as madeiras longitudinais são apenas para travamento do objeto.

\section{Figura 1 - Solarscópio}

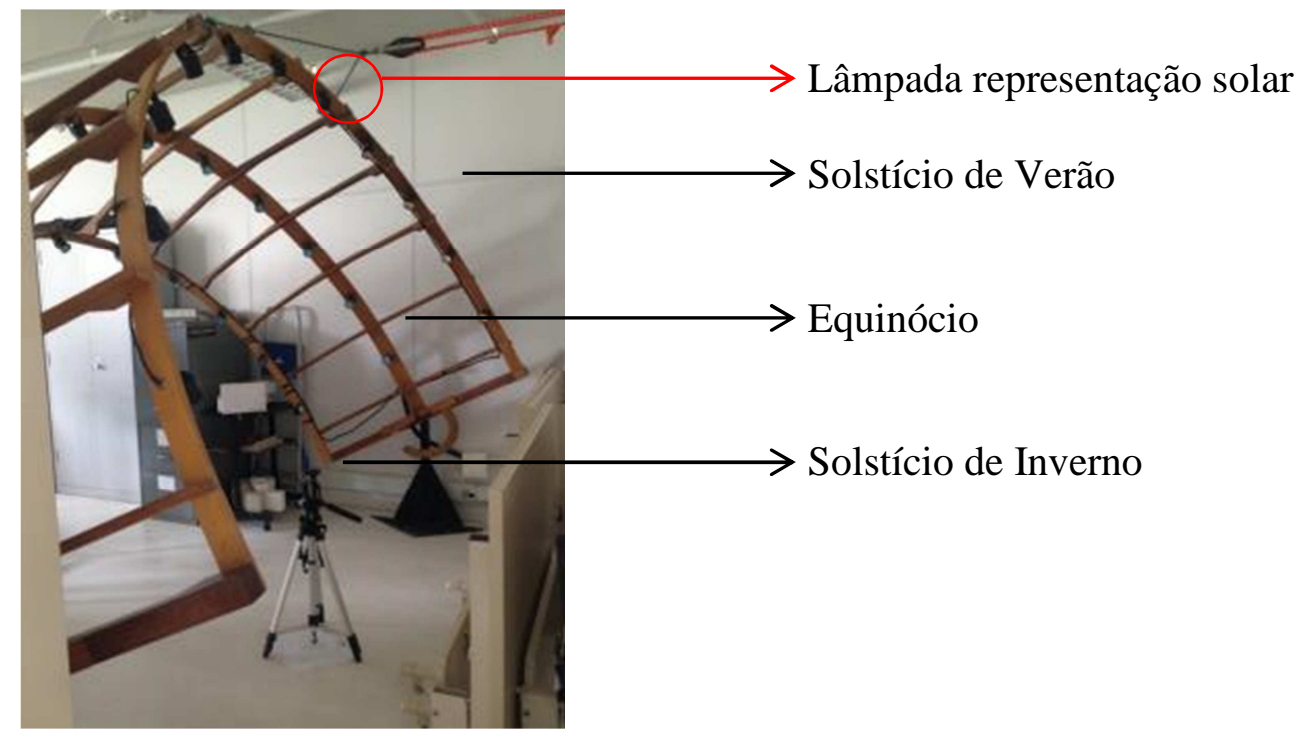

Fonte: Próprio Autor. 
Inicialmente foi testada a confiabilidade do método. Devido ao acesso a cartas solares horizontais em projeção equidistante da cidade em estudo posicionou-se o solarscópio na latitude a ser estudada e obteve-se, com a lente olho de peixe posicionada na horizontal, uma imagem que fosse compatível a carta solar horizontal equidistante. $\mathrm{Ou}$ seja, a câmera fotográfica com lente olho de peixe foi posicionada no centro do equipamento, sob um tripé com altura igual a 80 centímetros do chão à base da lente, com a lente olho de peixe alinhada ao inicio do madeiramento do solarscópio como mostra a Figura 2.

\section{Figura 2 - Posição da Câmera Fotográfica com Lente Olho de Peixe - alinhada com o solarscópio e a imagem adquirida pela foto.}
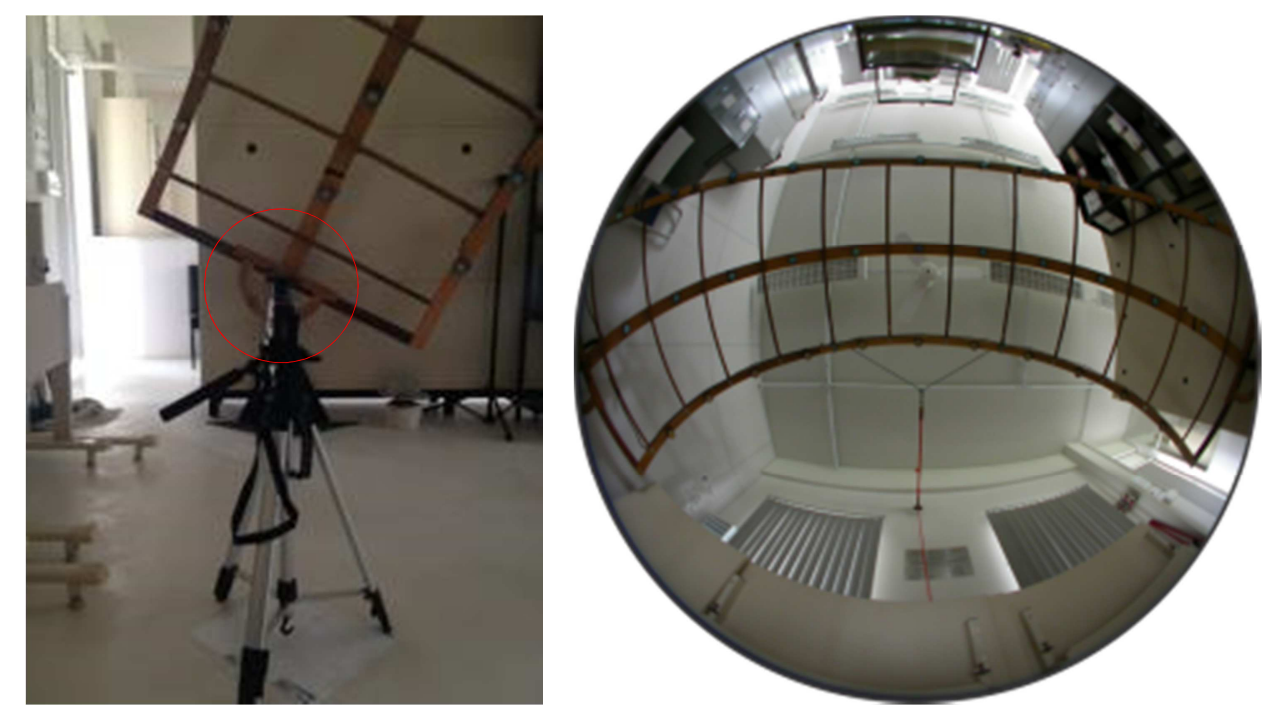

Fonte: Próprio Autor.

A Figura 3 mostra a foto horizontal do solarscópio que foi carregada no programa AutoCAD 2014 no arquivo da carta solar horizontal equidistante, editando a imagem para que tivesse um raio igual ao da carta solar de 1 metro.

Figura 3 - Foto horizontal do solarscópio e carta solar horizontal no programa AutoCAD 2014

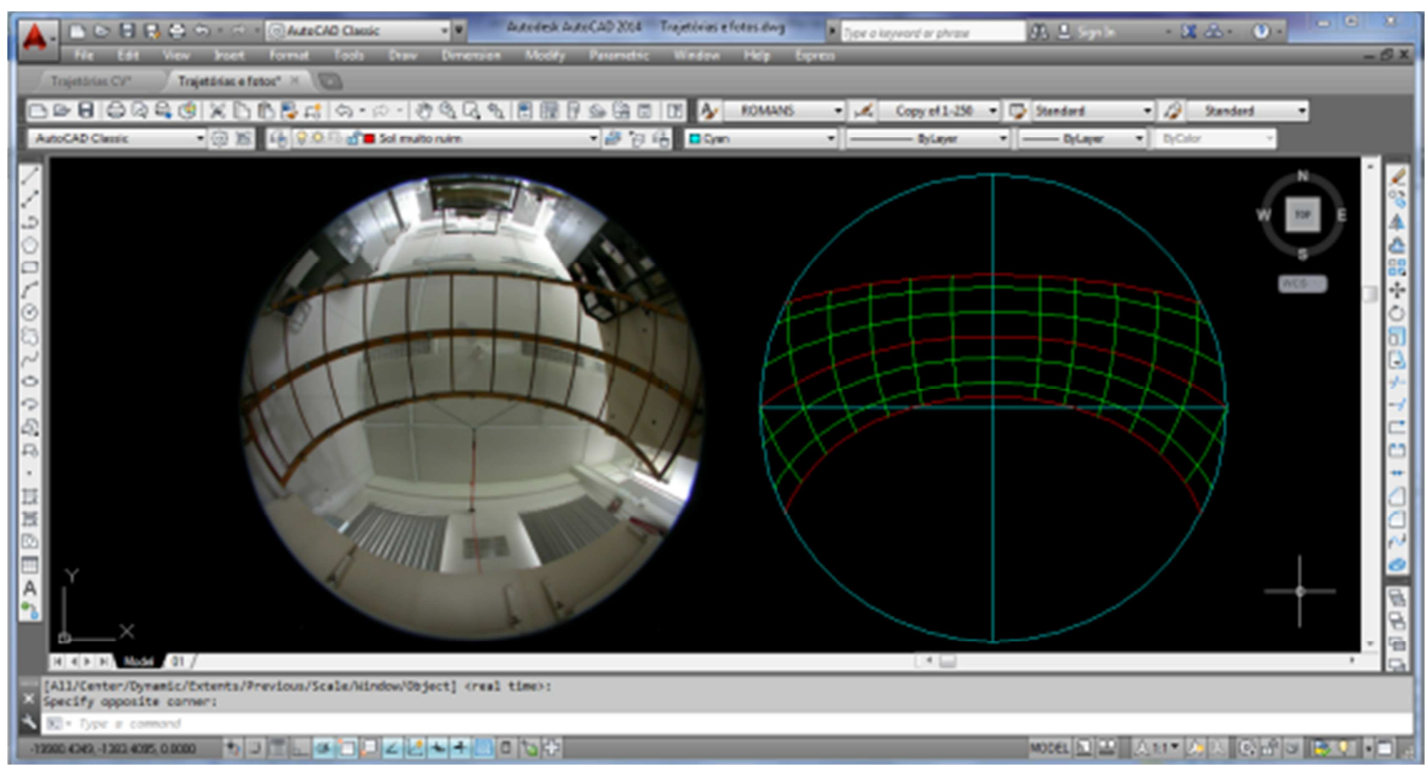

Fonte: Próprio Autor. 
Após isso se sobrepôs a carta solar a imagem do solarscópio comparando os traçados dos solstícios e equinócio e a localização das lâmpadas. Como se pode ver nas Figuras 4 e 5 houve compatibilidade entre a carta solar horizontal equidistante e a fotografia do solarscópio, ambas com latitude respectiva a cidade de estudo.

Figura 4 - Sobreposição carta solar equidistante e fotografia solarscópio

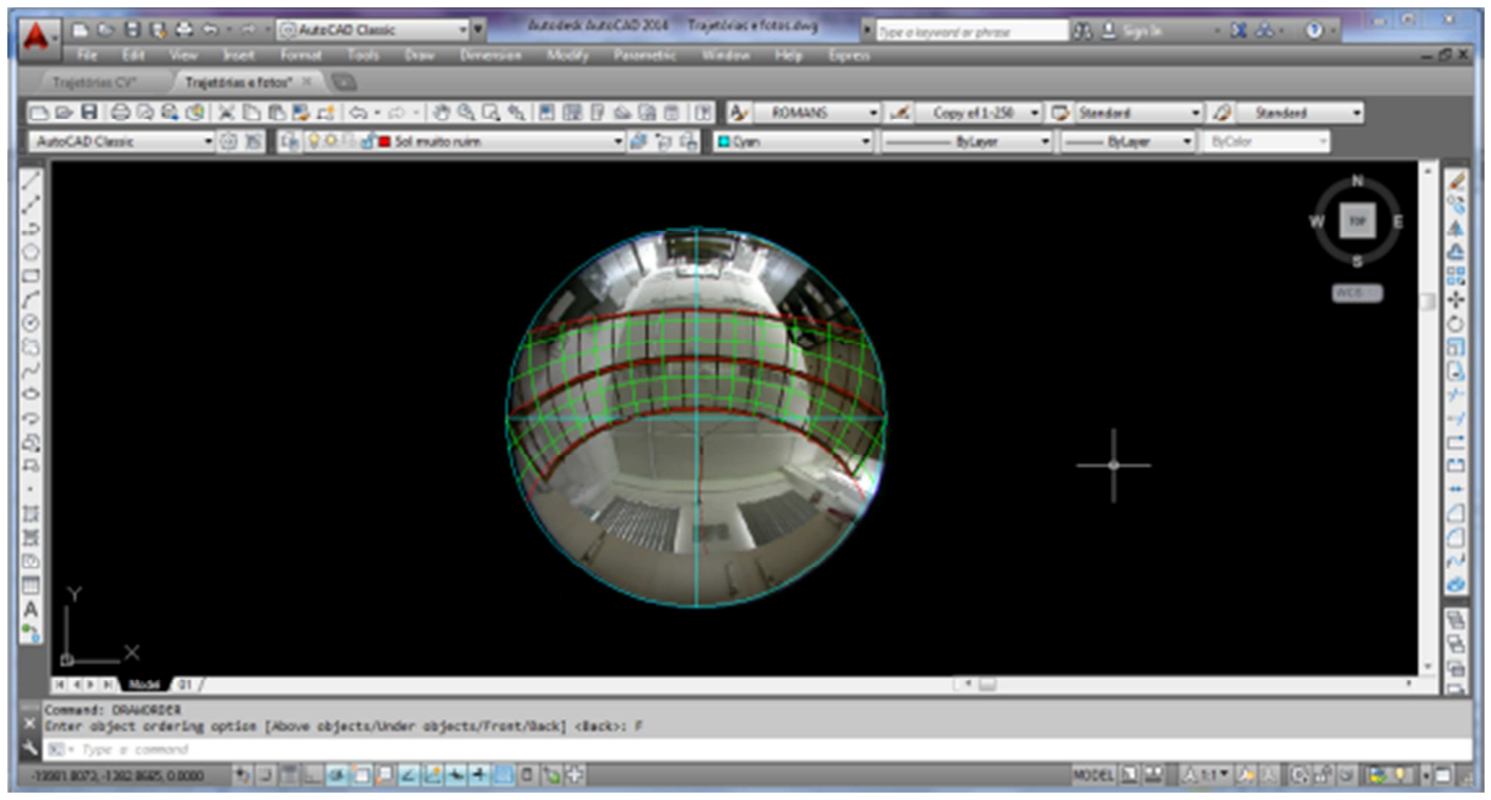

Fonte: Próprio Autor.

Figura 5 - Foto horizontal do solarscópio, carta solar horizontal equidistante e sobreposição das imagens - Validação do método
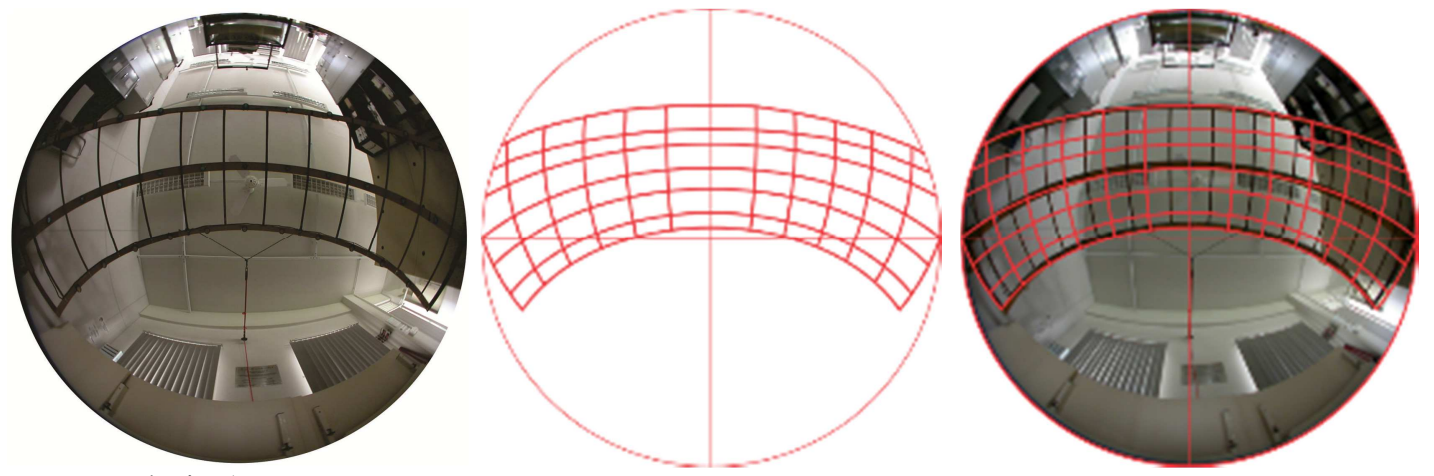

Fonte: Próprio Autor.

Portanto, comprovou-se a viabilidade do método para execução das cartas solares verticais equidistantes correspondentes aos campos visuais. Reforçando que $o$ solarscópio utilizado para desenvolver as cartas solares possui entre os pontos que demarcam as horas, madeiras de travamento para estabilidade do mecanismo. Ou seja, os pontos a serem considerados para demarcar os traços das horas são de lâmpada a lâmpada, entre os travamentos.

\subsection{Elaboração das cartas solares verticais equidistantes}

Comprovada a confiabilidade do método, mapeou-se os equipamentos de lazer das praças a serem estudados, obtendo as direções predominantes de campo visual. 
Os equipamentos analisados foram: mesas de jogos de xadrez, academias ao ar livre, bancos e playground, totalizando 44 equipamentos, sendo: 35 na primeira praça e 9 na segunda.

Como mostra a Figura 7, foram encontradas 18 direções de campo visual: Norte, Sul, Leste, Oeste, $+/-15^{\circ}$ Norte, $+/-15^{\circ} \mathrm{Sul},+/-15^{\circ}$ Leste, $+/-15^{\circ}$ Oeste, Nordeste, Noroeste, Suldeste, Suldoeste, $-22,5^{\circ}$ Sul e $-10^{\circ}$ Oeste.

O presente trabalho considera os campos visuais perpendiculares ao chão, com o usuário posicionado a direção imposta pelo equipamento de lazer, sem considerar possíveis modificações de campo visual geradas por "movimentos de pescoço" dos usuários.

Figura 6 - Mapeamento das direções dos campos visuais a serem estudados

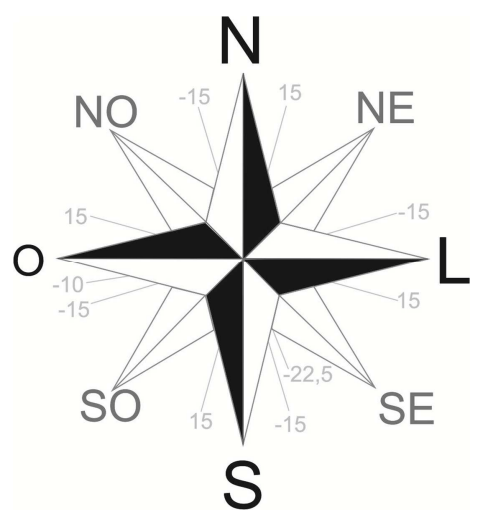

Fonte: Próprio Autor.

Após o mapeamento das direções para elaboração das cartas solares verticais equidistantes, foi feita a impressão das direções e desenhada no centro do solarscópio como guia para o posicionamento da máquina fotográfica.

A máquina fotográfica foi posicionada, com auxilio de um tripé, de modo que o centro da lente estivesse alinhado ao centro longitudinal e vertical do solarscópio.

Foram então capturadas as fotos para cada sentido de campo visual, totalizando 18 fotografias como podemos ver a seguir na Figura 8. 
Figura 7 - Fotografias para execução das cartas solares verticais equidistantes

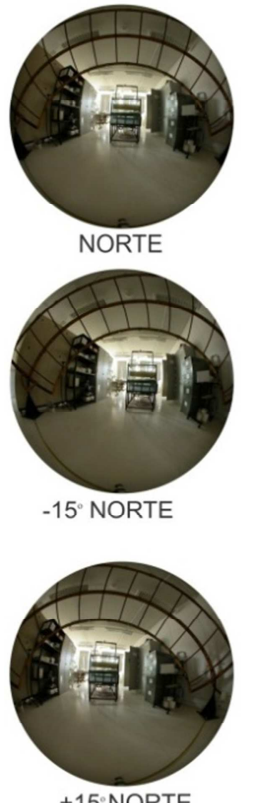

$+15^{\circ}$ NORTE
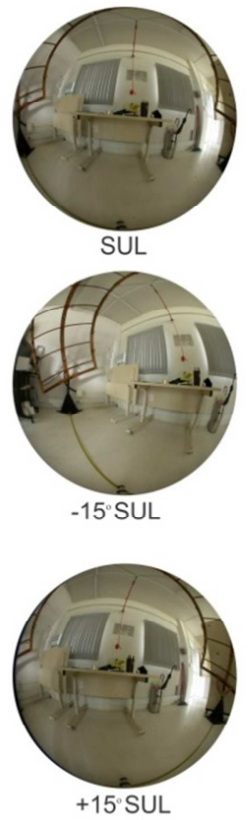
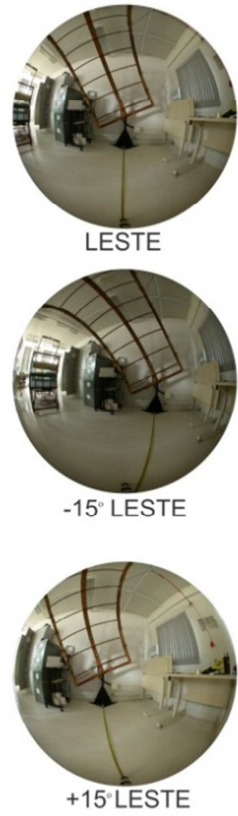

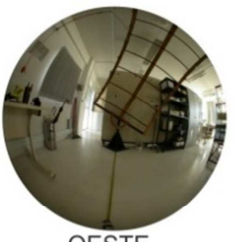

OESTE
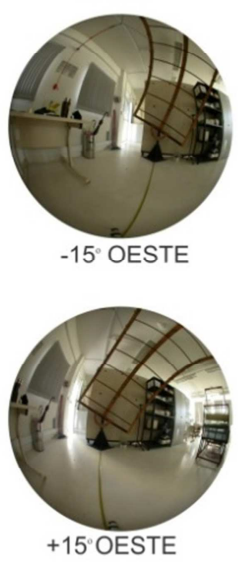
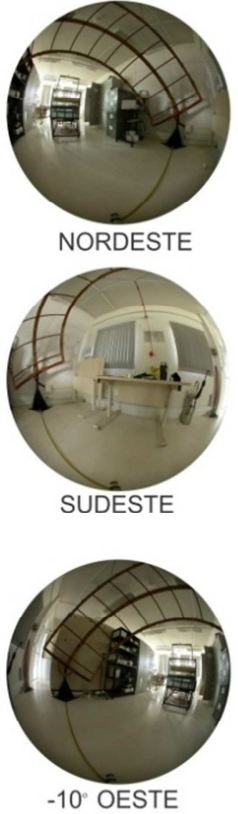
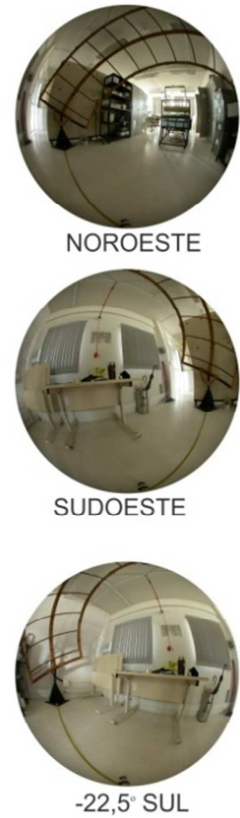

Fonte: Próprio Autor.

O procedimento escolhido para o desenho das cartas solares levou em conta a busca por uma ferramenta que possa ser desenvolvida de forma rápida e que seja utilizada para análises qualitativas. A Figura 9 demonstra como é o desenho no momento em que está sendo desenvolvido, onde cada fotografia do solarscópio é carregada no programa AutoCAD 2014 e com o comando stretch as formata com raio igual a 1 metro. Em seguida é feita uma circunferência de mesmo raio e com as indicações de Norte, Sul, Leste e Oeste, que é sobreposta à imagem, com o comando pline, que gera linhas e arcos contínuos, desenha-se primeiro os arcos que representam os solstícios e equinócio, em seguida unindo os pontos das lâmpadas, foram traçadas as linhas que representam as horas dos dias, completando o desenho da carta solar vertical.

Figura 8 - Desenho técnico da carta solar no programa AutoCAD 2014.

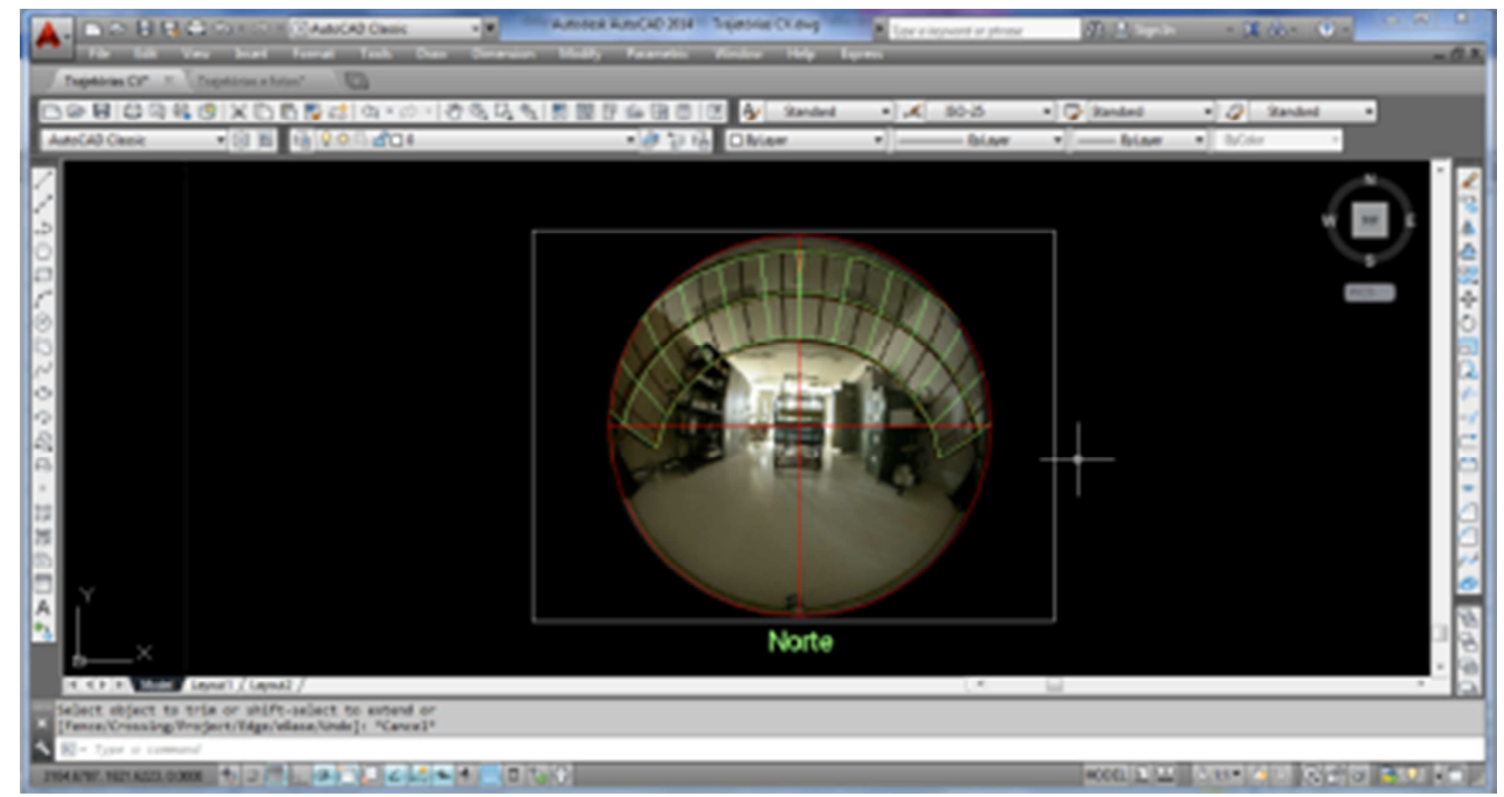

Fonte: Próprio Autor. 
Cada fotografia do solarscópio passou por este procedimento. A Figura 10 mostra todas as cartas solares verticais em projeção equidistante que foram desenvolvidas, cada uma representando uma direção de campo visual.

Figura 9 - Cartas Solares Verticais Equidistantes

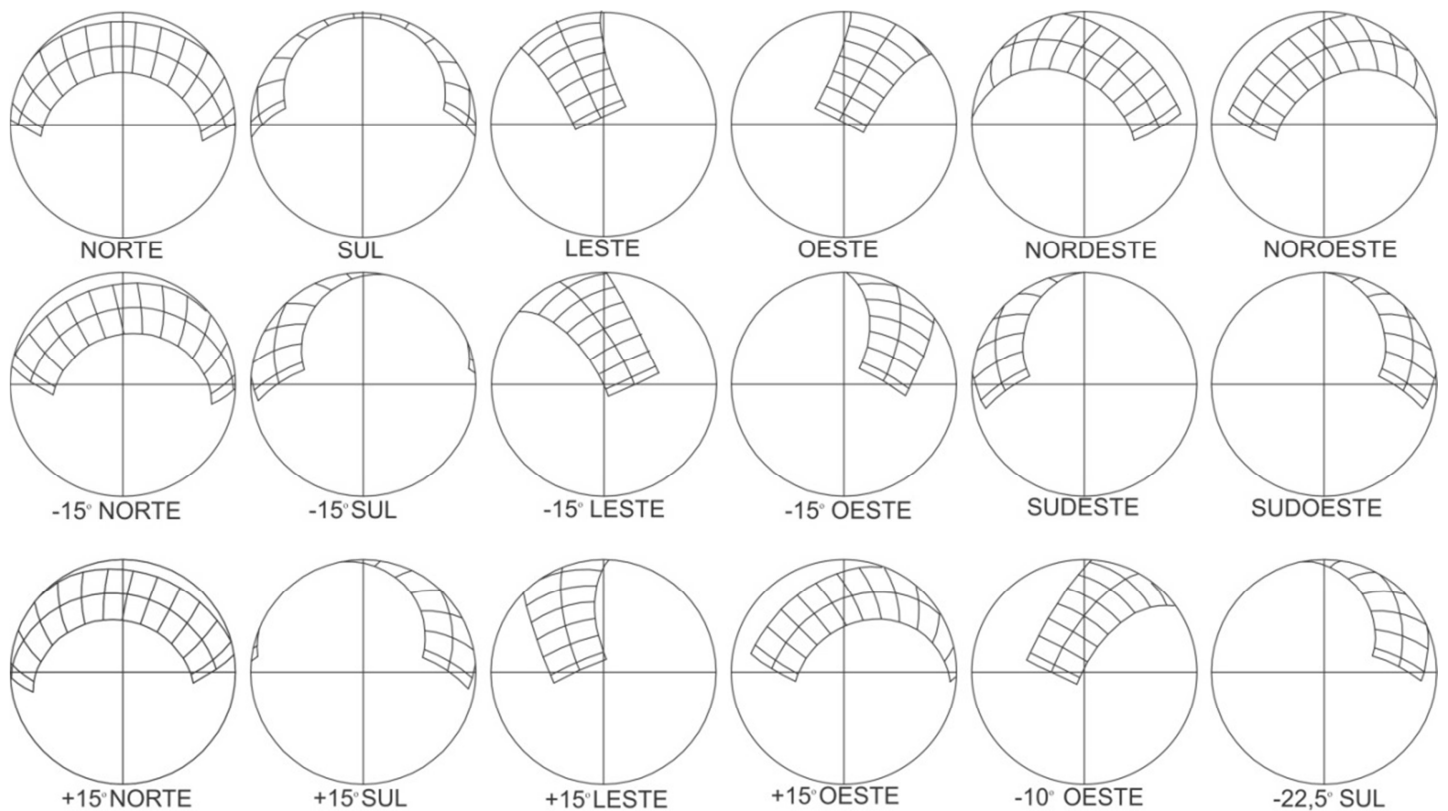

Fonte: Próprio Autor.

Com a carta solar vertical equidistante pronta superpõe-se a mesma as imagens de campo visual para aquela mesma direção, podendo deste modo extrair dados qualitativos, quanto à presença da luz direta do sol no campo visual estudado, assim como a qualidade e posição do sombreamento para o campo visual e o equipamento de lazer que está sendo estudado.

Propõe-se junto a essa ferramenta, utilizar como complemento o zoneamento do campo visual (PANERO; ZELNICK, 2006; BACKER; STEEMERS, 2002), como observado na imagem a seguir, divide o mesmo em 3 zonas distintas: a zona de visão central, a qual fornece a maior acuidade visual e é delimitada por um ângulo sólido de $1^{\circ}$; a zona chamada de ergorama que é formada por um ângulo sólido de $60^{\circ}$, onde se obtém a percepção de profundidade e a distinção cromática; a terceira zona chamada de panorama, onde os objetos são difíceis de distinguir quando estáticos (VÁSQUEZ, 2011). 


\section{Figura 10 - Zoneamento do Campo Visual}

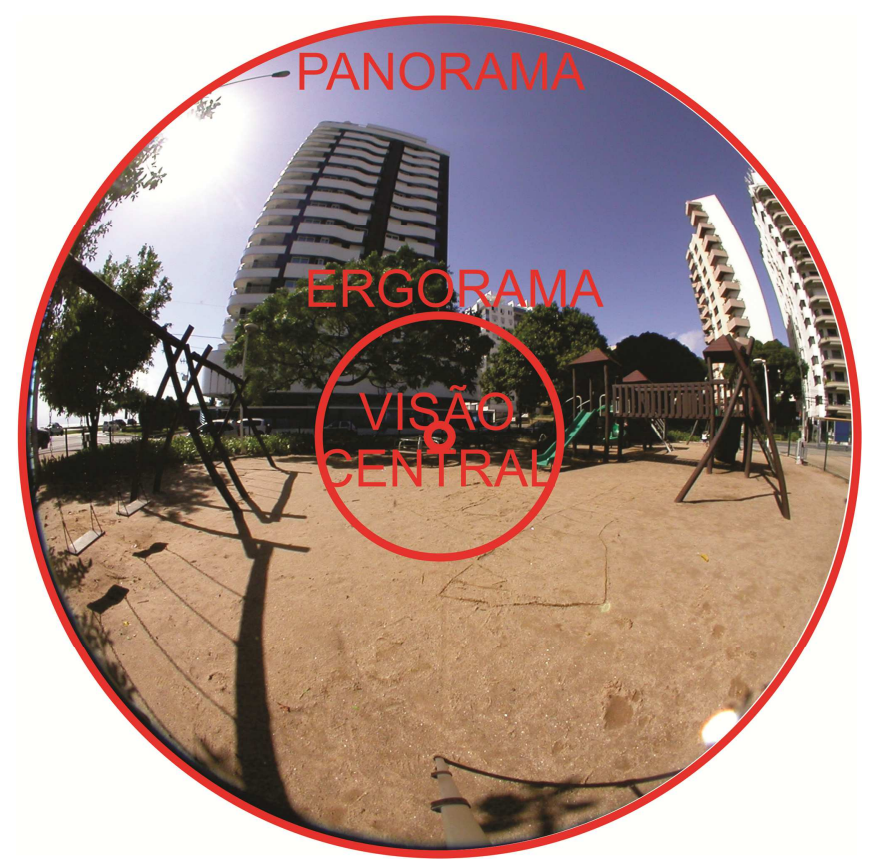

Fonte: Próprio Autor.

\section{EXEMPLO DE UTILIZAÇÃO DA CARTA SOLAR VERTICAL EQUIDISTANTE}

Buscando ilustrar a utilização da ferramenta, tomaram-se como exemplo dois equipamentos, primeiramente uma das posições de uma mesa de jogos de xadrez com campo visual direcionado para Leste e a outra um banco em um playground direcionado a Noroeste. A altura dos campos visuais considerada foi de uma pessoa adulta com 1,70 metros e a altura dos olhos ao chão igual a aproximadamente 1,10 metros, com banco possuindo 45 centímetros de altura (ABNT, 2004).

Como podemos visualizar na Figura 12, se o usuário mantiver seu campo de visão estático, provavelmente não haverá a possibilidade de ocorrência de ofuscamento, pois o entorno e a vegetação geram o bloqueio da presença da luz direta do sol, tanto na zona Ergorama quanto na zona Central de visão. Porém se este equipamento virado a Leste não possuísse um entorno denso, haveria grandes chances de ocorrência de ofuscamento causado pela luz direta do sol. 
Figura 11 - Exemplo 1: Campo visual direcionado a Leste

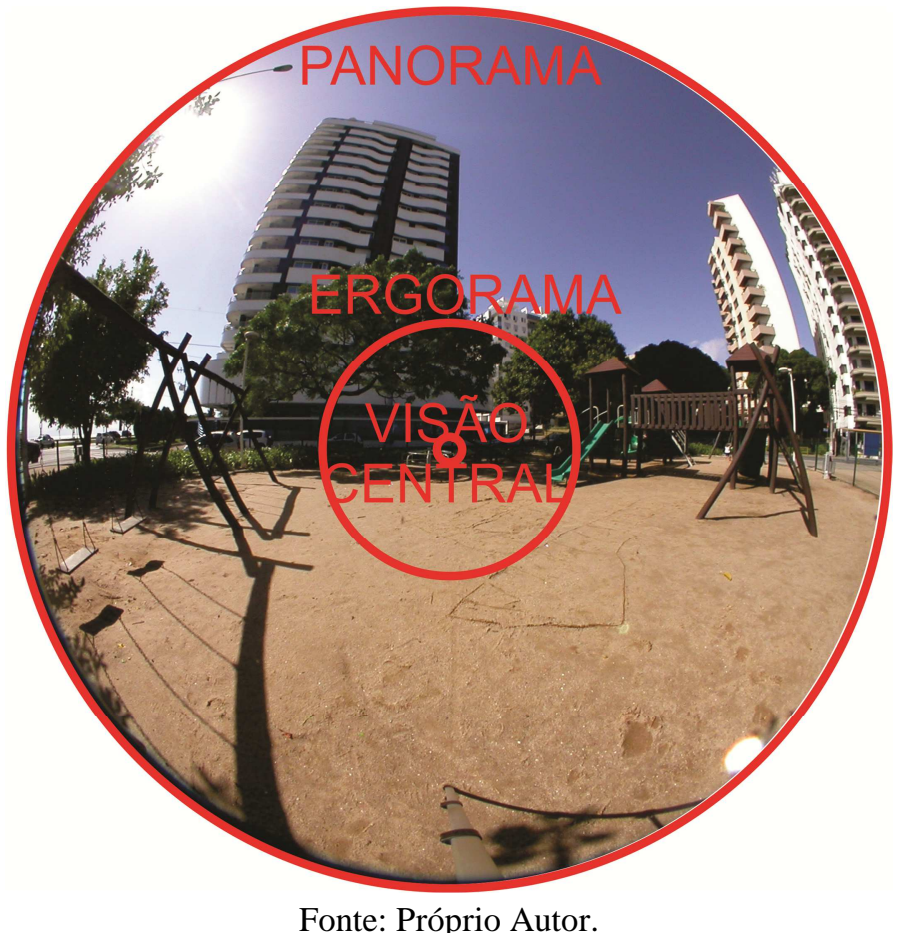

Ao analisar o segundo exemplo, representado pela Figura 13 podemos concluir que não há possibilidade de ocorrência de ofuscamento pela luz direta do sol, visto que o gráfico do movimento aparente do sol não está diretamente presente nas zonas de visão onde possa haver ofuscamento, mesmo se o usuário movimentar seu campo de visão para cima provavelmente não haverá a possibilidade de ocorrência de ofuscamento visto que há a copa da árvore está bloqueando a insolação direta.

\section{Figura 12 - Exemplo 2: Campo visual direcionado a Noroeste}

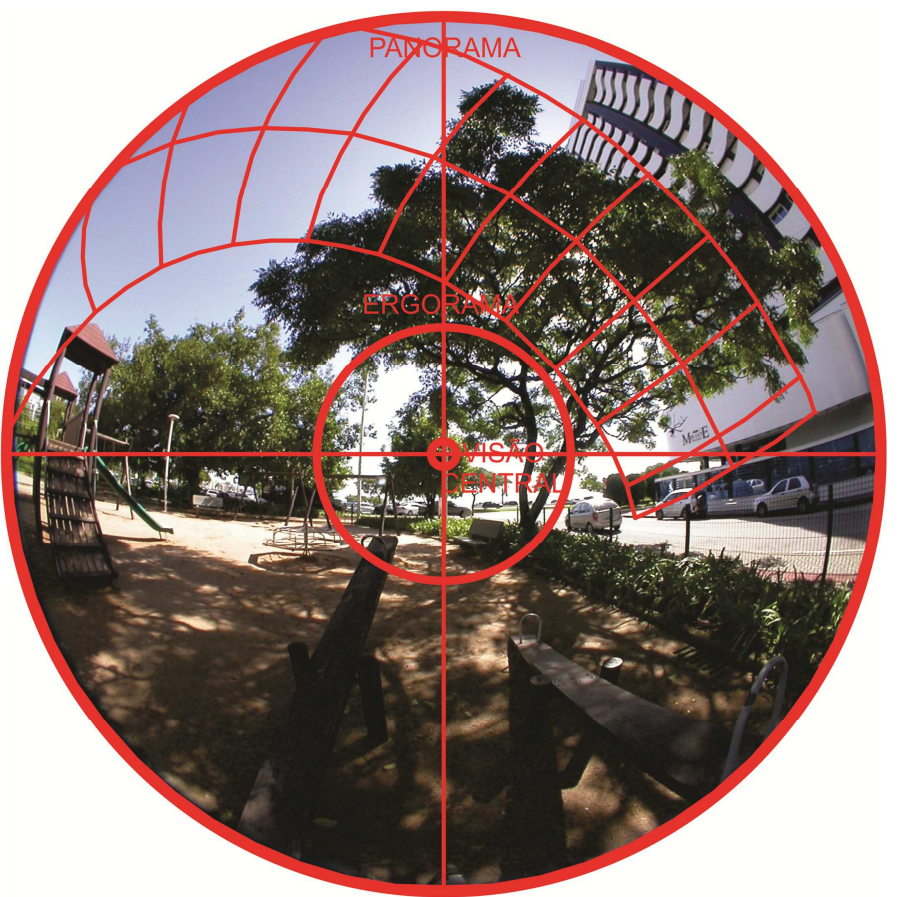

Fonte: Próprio Autor. 


\section{CONSIDERAÇÕES FINAIS}

Os arquitetos e urbanistas no momento inicial de seus projetos buscam ferramentas que os levem a tirar conclusões qualitativas do espaço de implantação. Deste modo, a ferramenta descrita e o método para adquiri-la buscam auxiliar estes projetistas na análise primária do movimento aparente do sol e sua posição em relação ao campo visual gerado por determinado equipamento.

Esta análise pode proporcionar o auxilio a ocasiões de podas de árvores ou na localização do plantio de vegetações, além de mostrar o comportamento do entorno quanto ao bloqueio ou não da luz direta do sol no campo visual.

Com o ajuste da latitude do solarscópio, pode-se utilizar o método descrito para desenvolver a carta solar vertical em projeção equidistante para as cidades em que se deseja. Porém, esta não serve como ferramenta quantitativa, pois a forma gráfica que é desenvolvido o desenho final da carta solar não é totalmente preciso.

Propõe-se complementar o estudo com análises do sombreamento utilizando fotos horizontais do espaço urbano sobrepondo-as a carta solar horizontal, assim como uma análise do ambiente luminoso noturno. Portanto, com a carta solar vertical em projeção equidistante e as análises complementares, pode-se propor uma melhor implantação dos equipamentos de lazer em praças públicas, além de possíveis podas de árvores ao plantio de novas espécies, qualificando deste modo o espaço urbano.

\section{REFERÊNCIAS}

ABNT - ASSOCIAÇÃO BRASILEIRA DE NORMAS TÉCNICAS. NBR 9050:2004 Acessibilidade a edificações, mobiliário, espaços e equipamentos urbanos. $2^{\mathrm{a}}$ ed. Rio de Janeiro, 2004. 91p. ICS 91.010.49.

BAKER, N; STEEMERS, K. Daylight design of buildings. London: James \& James Science Publishers, 2002. 245p.

FRÓES DA SILVA, L.L. Iluminação Pública no Brasil: aspectos energéticos e institucionais. 2006. 177f. Dissertação (Mestrado em Planejamento Energético) Coordenação dos Programas de Pós-graduação de Engenharia da Universidade Federal do Rio de Janeiro - COPPE UFRJ, Rio de Janeiro, 2006.

LABCON. Simulador do Movimento Aparente do Sol: Solarscópio. Disponível em: http://www.labcon.ufsc.br/equip_desenv_solarscopio.php Acesso em: jan 2014.

LIBERALINO, C. C. Praça: lugar de lazer: relações entre características ambientais e comportamentais na Praça Kalina Maia. 2011. 131p. Dissertação (Mestrado em Psicologia). Programa de Pós-Graduação em Psicologia. Universidade Federal do Rio Grande do Norte. Natal, RN, 2011. 131p.

MASBOUGI, A. Penser la ville par la lumière. Paris: Editors de la Villette, 2004.

MASCARÒ, L. A iluminação do espaço urbano. Revista RUA. v.10 p. 38-43, 2006. Porto Alegre, RS.

MIER, R. Por uma estrutura luminosa sustentável no território paulista: uma análise ao longo da estrada dos romeiros. Revista LABVERDE $n^{\circ}$ 7, 2013, p.13-37. ISSN 21792275. 
MOISINHO FILHO, E. F. MOISINHO FILHO, E. F. Patrimônio cultural e iluminação urbana em São Cristóvão. NUTAU/USP - $7^{\circ}$ Seminário Internacional Espaço Sustentável: Inovações em Edifícios e Cidades. Abril, 2008. Disponível em: http://www.usp.br/nutau/CD/157.pdf Acesso em: 28 fevereiro 2012.

PANERO, J.; ZELNIK, M. Las dimensiones humanas y los espacios interiores: Estándares Antropométricos. $7^{a}$ ed. México, D.F. Ed. G. Gili, S.A. de CV, 1996. 315p.

ROIZENBLATT, I. Critérios da iluminação elétrica urbana. 2009. 196 f. Tese (Doutorado em Arquitetura e Urbanismo). Programa de Pós-Graduação em Arquitetura e Urbanismo da Universidade Presbiteriana Mackenzie, São Paulo, 2009.

SCHMITZ, S. Introdução à história da iluminação pública em Florianópolis. Ágora, Florianópolis, UFSC/UDESC, v.25, p.14-16, 1997.

VÁSQUEZ, N. G.. Ensaio de caracterização dos campos visuais de crianças em salas de aula: identificação dos componentes arquitetônicos de maior influência. 2011. 207 p. Dissertação (Mestrado em Arquitetura e Urbanismo). Universidade Federal de Santa Catarina. Florianópolis, SC, 2011. 